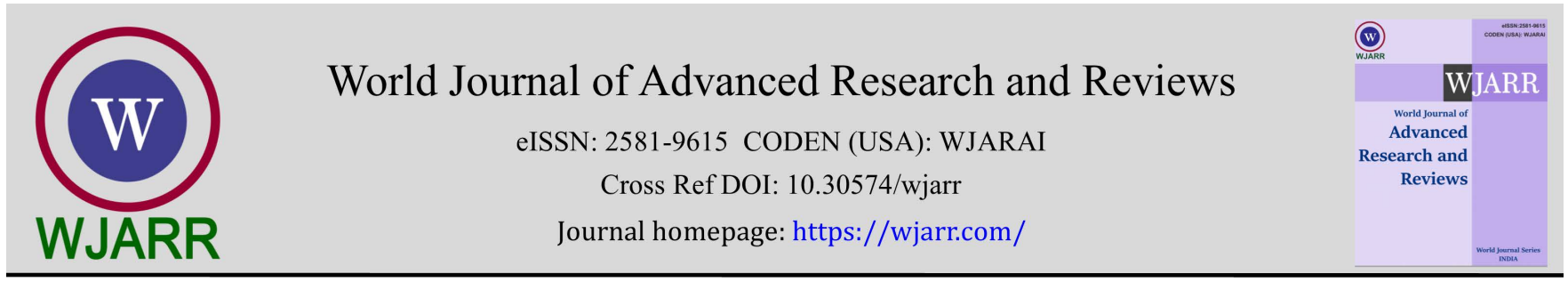

(RESEARCH ARTiClE)

Check for updates

\title{
Denture characteristics, oral hygiene practice and periodontal changes of partial denture wearers and non-denture wearers in a Teaching Hospital- A comparative study
}

\author{
Omotayo Adebola Oremosu ${ }^{1}$ and Modupeoluwa Omotunde Soroye ${ }^{2, *}$ \\ ${ }^{1}$ Department of Restorative Dentistry University of Lagos, Lagos State. \\ 2 Department of Preventive Dentistry Faculty of Dentistry University of Port Harcourt, Port Harcourt, Rivers State.
}

World Journal of Advanced Research and Reviews, 2022, 13(01), 077-085

Publication history: Received on 29 November 2021; revised on 01 January 2022; accepted on 03 January 2022

Article DOI: https://doi.org/10.30574/wjarr.2022.13.1.0761

\begin{abstract}
Background: There can be localized periodontal inflammation around abutment teeth of dentures as a result of plaque accumulation. This study assessed the periodontal changes of removable partial denture wearers compared to that of non-denture wearers.

Methodology: Participants were recruited from the prosthodontic and restorative outpatient clinics of Lagos University Teaching Hospital. The self-administered questionnaire was used to collect information on socio-demographics, denture characteristics, periodontal changes and oral hygiene practice of participants. Periodontal status assessed included gingival inflammation, plaque accumulation and tooth mobility. Data was analyzed using SPSS version 20 (IBM SPSS Armonk, New York) and presented as frequencies and percentages. Test for significance was done using Chi-square statistics, and the level of statistical significance was set at $\mathrm{P}<0.05$.

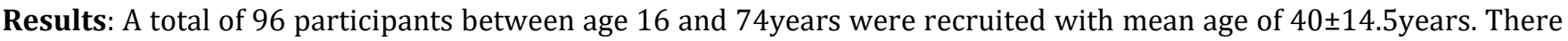
were 56 females and 40 males (F:M; 1.4:1). Fifty-four denture wearers and forty-two non-denture wearers were recruited into the study. Among participants wearing partial denture, 49(90.7\%) had gingival inflammation; 45(91.8\%) had mild inflammation compared to $4.8 \%$ participants who are non-denture wearers. $29(53.7 \%)$ denture wearers had fair oral hygiene while most 31(73.8\%) non-denture wearers had excellent oral hygiene. Abutment teeth in denture wearers had tooth recession; mostly on the upper arch and also posteriorly.
\end{abstract}

Conclusion: The periodontal inflammation, tooth recession and mobility in denture wearers were worse compared to non-denture wearers. Thus, they need to be motivated for more adequate oral hygiene practices and have regular recall system to monitor their periodontal health.

Keywords: Periodontal inflammation, Oral hygiene; Periodontal status; Removable partial denture

\section{Introduction}

There are various treatment modalities for partial edentulism. These includes implants, tooth-supported fixed prostheses like bridges, and removable partial dentures (RPDs) [1]. Removable partial dentures provide rapid solution, it is less costly and a conservative treatment when compared with other types of replacements [2]. While some disadvantages of RPD include development of dental caries especially root caries on abutment teeth, increased plaque and calculus accumulation [3].

\footnotetext{
${ }^{*}$ Corresponding author: Modupeoluwa Omotunde Soroye

Department of Preventive Dentistry Faculty of Dentistry University of Port Harcourt, Port Harcourt, Rivers State.

Copyright (C) 2022 Author(s) retain the copyright of this article. This article is published under the terms of the Creative Commons Attribution Liscense 4.0.
} 
It is important to practise regular oral and denture hygiene in order to maintain good oral hygiene on a long-term use in order to maintain and retain the health and integrity of standing teeth and periodontal tissues [4]. Though a study had reported that RPD alone did not cause any additional oral pathology, and there was no effect on abutment teeth [5]. Some longitudinal studies reported that RPDs are associated with increased gingivitis, periodontitis, and abutment mobility [6,7]. Other studies also reported a correlation between RPDs and increased risk of periodontal diseases [8.9]. Therefore, proper denture use and care constitute important component not only for functional and aesthetic reasons, but also for the appropriate maintenance of the denture itself for RPD wearers and the health of the abutment and supporting periodontal tissues [10].

The periodontium consists of the supporting tissues of the teeth and is made up of the gingiva, the cementum, the alveolar bone and the periodontal ligament [11]. The gingiva can be inflamed as a result of accumulation of bacterial plaque, leading to gingivitis, if left untreated, result in periodontitis. In the early stages, periodontitis presents with gingival bleeding, gingival recession while in the advanced stage presents with tooth mobility, tooth migration and tooth loss. This will impair oral function, aesthetics and quality of life [12].

Tooth mobility can be as a result of disease progression in chronic periodontitis or as a result of chronic trauma to a tooth seen often in the use of RPDs. The PRDs especially when not properly fabricated can serve as nidus for plaque accumulation and this in addition to the trauma from their constant rocking, may result in periodontal disease [13].

Removable Partial Denture, is a common means of tooth replacement in Nigeria [14-16]. It is important that these prostheses are cleaned and maintained as researches have shown that there is the need to clean dentures properly and acquire adequate oral hygiene habits, despite age, social status, education, systemic diseases, and smoking [17-21]. The awareness and motivation of RPD wearers to maintain high oral cleanliness is very important for periodontal health [4]. Thus, there is a need to investigate the effect of partial denture on standing teeth. This study aimed to investigate the denture characteristics, oral hygiene practice and extent of periodontal inflammation around abutment teeth in patients who wear partial dentures and to compare with those who are non-wearers.

\section{Material and methods}

The study was a descriptive cross-sectional study of all patients attending the Prosthodontics and Restorative outpatient clinics in the Lagos University Teaching Hospital, Idi-Araba, Lagos between March and June, 2019. All participants who attended the clinics between March and June 2019 were recruited for the study.

Self-administered questionnaire was used to obtain information such as socio-demographics and oral hygiene practice from the participants. Information on denture characteristics and periodontal changes of all participants that used dentures were also collected.

Patients who wanted to have other restorative treatment but did not use dentures were included in the study after obtaining consent from them. They were matched for age and gender and recruited consecutively. Only participants who had worn dentures for more than six months were included in the study group. The control group included participants not wearing dentures.

All clinical examination was carried out by a periodontist using Periodontal indices, these included Gingival index (GI), Plaque index (PI) and presence of absence of gingival recession and tooth mobility of abutment teeth of RPD wearers. The gingival index of Loe and Silness 1963 was used scoring 0, 1, 2, and 3 scores for no inflammation, mild, moderate and severe inflammation respectively. The participant's individual GI score was calculated by adding the GI for each tooth divided by total number of teeth examined and the score was recorded. The gingival index was then categorized into zero (0) when there is no inflammation, 0.1-1.0 for mild inflammation, 1.1-2.0 for moderate inflammation and 2.13.0 for severe inflammation.

Plaque index of Silness and Loe (1964) was used scoring 0 when there was no plaque, 1 for thin layer of plaque at gingival margin detected by scraping with a probe, 2 for moderate plaque that is visible at the gingival margin sparing the interdental spaces and 3 for abundant plaque at both the gingival margin and interdental spaces. This was then categorized into 0, 0.1-0.9, 1.0-1.9, 2.0-3.0 for excellent, good, fair, and poor hygiene respectively.

The data collected was analyzed using SPSS version 20 (IBM SPSS Armonk, New York) and presented as frequencies and percentages. Test for significance was done using Chi-square statistics, and the level of statistical significance was set at $\mathrm{P}<0.05$. 


\section{Results}

Table 1 Participant's demographics

\begin{tabular}{|l|l|l|l|l|l|}
\hline Variables & $\begin{array}{l}\text { Denture wearers } \\
\text { N (\%) }\end{array}$ & Non- dentures wearers N (\%) & Total & $\chi \mathbf{2}$ & $\mathbf{P}$ \\
\hline Age & & & & & \\
\hline$<20$ & $2(3.7)$ & $2(4.8)$ & $4(4.2)$ & 14.73 & $0.02^{*}$ \\
\hline $21-30$ & $9(16.7)$ & $19(45.1)$ & $28(29.2)$ & & \\
\hline $31-40$ & $12(22.2)$ & $12(28.6)$ & $24(25.0)$ & & \\
\hline $41-50$ & $14(25.9)$ & $5(11.9)$ & $19(19.7)$ & & \\
\hline $51-60$ & $8(14.8)$ & $2(4.8)$ & $10(10.4)$ & & \\
\hline $61-70$ & $6(11.1)$ & $1(2.4)$ & $7(7.3)$ & & \\
\hline$>70$ & $3(5.6)$ & $1(2.4)$ & $4(4.2)$ & & \\
\hline Gender & & & & & \\
\hline Male & $22(40.7)$ & $18(42.9)$ & $40(41.7)$ & 0.05 & 0.50 \\
\hline Female & $32(59.3)$ & $24(57.1)$ & $56(58.3)$ & & \\
\hline Ethnicity & & & & 11.84 & $0.003^{*}$ \\
\hline Yoruba & $29(53.7)$ & $26(61.9)$ & $55(57.3)$ & & \\
\hline Hausa & $2(3.7)$ & $9(21.4)$ & $11(11.5)$ & & \\
\hline Igbo & $23(42.6)$ & $7(16.7)$ & $30(31.2)$ & & \\
\hline Total & $54(100.0)$ & $42(100)$ & $96(100.0)$ & & \\
\hline
\end{tabular}

A total of 96 participants took part in this study. There were 56 females and 40 males, giving a F:M ratio of 1.4:1. The age range was between 16 and 74 years. About a quarter of the denture wearers were in the $5^{\text {th }}$ decade of life. Statistical analysis of age and ethnicity of participants was significant. Denture wearing cut across all age group and all ethnicity in Nigeria.

Table 2 Denture Characteristics of wearers

\begin{tabular}{|l|l|l|}
\hline Variables & Frequency & Percentage \\
\hline Denture Type & & \\
\hline Acrylic & 52 & 96.2 \\
\hline Flexible & 1 & 1.9 \\
\hline Metal Base & 1 & 1.9 \\
\hline Denture Arch & & \\
\hline Upper & 51 & 94.4 \\
\hline Lower & 2 & 3.7 \\
\hline Both & 1 & 1.9 \\
\hline Denture Location & & \\
\hline Anterior & 30 & 55.6 \\
\hline
\end{tabular}




\begin{tabular}{|l|l|l|}
\hline Posterior & 19 & 35.2 \\
\hline Both & 5 & 9.2 \\
\hline Duration of denture wearing & & \\
\hline 6months - 12 months & 7 & 13.0 \\
\hline 13months - 5years & 26 & 48.1 \\
\hline >5 years & 21 & 38.9 \\
\hline Do you take out denture before sleeping? & & \\
\hline Yes & 49 & 90.7 \\
\hline No & 5 & 9.3 \\
\hline When do you take out your denture? & & \\
\hline Morning alone & 9 & 16.7 \\
\hline Night alone & 27 & 50.0 \\
\hline Anytime & 18 & 33.3 \\
\hline Where do you keep your denture? & & \\
\hline On a clean surface & 16 & 29.6 \\
\hline In a container with water & 38 & 70.4 \\
\hline How often do you clean your denture? & & \\
\hline Once daily & 29 & 53.7 \\
\hline Several times daily & 22 & 40.7 \\
\hline Alternate days & 2 & 3.7 \\
\hline Occasionally & 1 & 1.9 \\
\hline What item do you use to clean your denture? & & \\
\hline Toothbrush and paste & 23 & 42.5 \\
\hline Toothbrush and toilet soap & 17 & 31.5 \\
\hline Toothbrush and medicated soap & 8 & 14.8 \\
\hline Salt and water & 1 & 1.9 \\
\hline Water & 54 & 6.3 \\
\hline Total & \\
\hline
\end{tabular}

Fifty-two (96.2\%) used acrylic dentures. The dentures 51(94.4\%) were mostly used in the upper arch and more than half $30(55.6 \%)$ replaced teeth in the anterior region. Majority of denture wearers $47(87 \%)$ have worn dentures for over 12 months. As regards denture use and hygiene, 5(9.3\%) participants wear their dentures while sleeping, two thirds $38(70.4 \%)$ of them keep them in water while not in use while half 29 (53.7\%) of participants clean their dentures once daily. 17(13.5\%) clean their dentures with toothbrush and toilet soap.

More participants 51(94.4\%) among denture wearers use toothbrushes and fluoridated toothpastes to clean their teeth when compared with those without dentures 28(66.2\%). 24(44.4\%) denture wearers clean their mouth twice a day while less than a fifth $8(19.1 \%)$ of non-denture wearers clean twice. This is statistically significant. Table 3.

Many $36(85.7 \%)$ of the non-denture wearers had done scaling and polishing in the past when compared to the denture wearers $36(66.7 \%)$. This is significant statistically. Table 3. 
Table 3 Participants' oral hygiene practice

\begin{tabular}{|c|c|c|c|c|c|c|}
\hline Variables & $\begin{array}{c}\text { Denture } \\
\text { Wearers N (\%) }\end{array}$ & $\begin{array}{c}\text { Non-denture wearers } \\
\text { N (\%) }\end{array}$ & \begin{tabular}{r|} 
Total \\
N (\%)
\end{tabular} & $\%$ & $\chi^{2}$ & $\mathbf{P}$ \\
\hline \multicolumn{7}{|l|}{ Cleaning items } \\
\hline Toothbrush and Paste & $51(94.4)$ & $28(66.2)$ & \multicolumn{2}{|c|}{$79(82.3)$} & 88.46 & $<0.0001$ \\
\hline Chewing stick and Toothbrush & $2(3.7)$ & $1(2.4)$ & \multicolumn{2}{|l|}{$3(3.1)$} & & \\
\hline Mouthwash only & 0 & $6(14.3)$ & \multicolumn{2}{|l|}{$6(6.3)$} & & \\
\hline Water and salt & $1(1.9)$ & $7(16.7)$ & \multicolumn{2}{|l|}{$8(8.3)$} & & \\
\hline \multicolumn{7}{|c|}{ Frequency of cleaning the mouth } \\
\hline Once & $30(55.6)$ & $31(73.8)$ & \multicolumn{2}{|c|}{$61(63.4)$} & 9.67 & $<0.0001$ \\
\hline Twice & $24(44.4)$ & $8(19.1)$ & \multicolumn{2}{|c|}{$32(33.3)$} & & \\
\hline Alternate days & 0 & $3(7.1)$ & \multicolumn{2}{|l|}{$3(3.1)$} & & \\
\hline \multicolumn{7}{|c|}{ Previous Scaling and Polishing (S\&P) } \\
\hline Yes & $36(66.7)$ & $36(85.7)$ & \multicolumn{2}{|c|}{$72(75.0)$} & 4.57 & 0.04 \\
\hline No & $18(33.3)$ & $6(14.3)$ & \multicolumn{2}{|c|}{$24(25.0)$} & & \\
\hline Total & 54 & $42(100)$ & \multicolumn{2}{|c|}{$96(100.0)$} & & \\
\hline \multicolumn{7}{|l|}{ Duration of last $S \& P$} \\
\hline$<6$ months & $18(50.0)$ & $14(38.9)$ & \multicolumn{2}{|c|}{$32(44.4)$} & 1.06 & 0.59 \\
\hline 6-12 months & $8(22.2)$ & $12(33.3)$ & \multicolumn{2}{|c|}{$20(27.8)$} & & \\
\hline$>2$ years & $10(27.8)$ & $10(27.8)$ & \multicolumn{2}{|c|}{$20(27.80$} & & \\
\hline Total & $36(100.0)$ & $36(100.0)$ & \multicolumn{2}{|c|}{$72(100.0)$} & & \\
\hline
\end{tabular}

Table 4 Periodontal status of abutment teeth in denture wearers compared to non-denture wearers

\begin{tabular}{|c|c|c|c|c|c|}
\hline Variables & $\begin{array}{c}\text { Denture } \\
\text { wearers } \\
\text { N (\%) }\end{array}$ & $\begin{array}{c}\text { Non-denture } \\
\text { wearers } \\
\text { N (\%) }\end{array}$ & $\begin{array}{l}\text { Total } \\
\text { N (\%) }\end{array}$ & $\chi^{2}$ & $\mathbf{P}$ \\
\hline \multicolumn{4}{|l|}{ Gingival inflammation } & 70.16 & $<0.0001$ \\
\hline Yes & $49(90.7)$ & $2(4.8)$ & $51(53.1)$ & & \\
\hline No & $5(9.3)$ & $40(95.2)$ & $45(46.1)$ & & \\
\hline \multicolumn{4}{|l|}{ Gingival index } & 1.21 & 0.27 \\
\hline Mild (0.1-1.0) & $45(91.8)$ & $2(100.0)$ & $47(83.9)$ & & \\
\hline Moderate $(1.1-2.0)$ & $4(8.2)$ & $0(0.0)$ & $4(16.1)$ & & \\
\hline \multicolumn{4}{|l|}{ Plaque index (Hygiene) } & 37.20 & $<0.0001$ \\
\hline Excellent hygiene (0) & $9(16.7)$ & $31(73.8)$ & $40(41.7)$ & & \\
\hline Good hygiene (0.1-0.9) & $15(27.7)$ & $9(21.4)$ & $24(25.0)$ & & \\
\hline Fair hygiene (1.0-1.9) & $29(53.7)$ & $2(4.8)$ & $31(32.3)$ & & \\
\hline Poor hygiene (2.0-3.0) & $1(1.9)$ & 0 & $1(1.0)$ & & \\
\hline \multicolumn{4}{|l|}{ Recession } & 96.00 & $<0.0001$ \\
\hline
\end{tabular}




\begin{tabular}{|c|c|c|c|c|c|}
\hline Yes & $7(13.0)$ & 0 & $7(7.3)$ & & \\
\hline No & $47(87.0)$ & $42(100)$ & $89(92.7)$ & & \\
\hline Total & $54(100)$ & $42(100)$ & $96(100.0)$ & & \\
\hline \multicolumn{4}{|l|}{ Recessed Teeth } & 96.00 & $<0.0001$ \\
\hline Anterior teeth & $1(14.3)$ & $0(0.0)$ & $1(14.3)$ & & \\
\hline Posterior teeth & $6(85.7)$ & $0(0.0)$ & $6(85.7)$ & & \\
\hline \multicolumn{4}{|c|}{ Location of Recessed teeth } & 96.00 & $<0.0001$ \\
\hline Upper arch & $4(57.1)$ & $0(0.0)$ & 40557.1 & & \\
\hline Lower arch & $2(28.6)$ & $0(0.0)$ & $2(28.6)$ & & \\
\hline Upper \& lower & $1(14.3)$ & $0(0.0)$ & $1(14.3)$ & & \\
\hline Total & $7(100)$ & $0(0.0)$ & $7(100.0)$ & & \\
\hline \multicolumn{4}{|c|}{ Oral Hygiene index } & 0.22 & 0.64 \\
\hline Good & $27(50.0)$ & $19(45.2)$ & $46(47.9)$ & & \\
\hline Fair & $27(50.0)$ & $23(54.8)$ & $50(52.1)$ & & \\
\hline \multicolumn{4}{|l|}{ Tooth Mobility } & 4.31 & 0.37 \\
\hline Yes & $7(13.0)$ & $1(2.4)$ & $8(8.3)$ & & \\
\hline No & $47(87.0)$ & $41(97.6)$ & $88(91.7)$ & & \\
\hline Total & $54(100.0)$ & $42(100.0)$ & $96(100.0)$ & & \\
\hline
\end{tabular}

Most $49(90.7 \%)$ of denture wearers had gingival inflammation around abutment teeth and statistical analysis showed a significance. $45(91.8 \%)]$ of the participants' abutment teeth had mild inflammation compared to $2(4.8 \%)$ of nondenture wearers. More than half 29(53.7) of the denture wearers had fair oral hygiene while most 31(73.8\%) of the non-denture wearers had excellent oral hygiene. Abutment teeth in denture wearers had tooth recession; mostly on the upper arch and on posterior teeth. Tooth mobility was present in $7(13,0 \%)$ of denture wearers compared to nondenture wearers $1(2.4 \%)$.

Table 5 Mean scores of periodontal parameters of denture wearers

\begin{tabular}{|l|c|c|c|}
\hline \multicolumn{1}{|c|}{ Variables (Mean $\mathbf{\pm S D}$ ) } & Denture wearers & Non-denture wearers & P \\
\hline GI (Loe/Silness) & $0.61 \pm 0.47$ & $0.05 \pm 0.22$ & $<0.0001$ \\
\hline PLI (Silness/Loe) & $0.76 \pm 0.40$ & $0.15 \pm 0.28$ & 0.003 \\
\hline OHI-S (Green and Vermillion) & $1.29 \pm 0.66$ & $1.47 \pm 1.03$ & $<0.0001$ \\
\hline TM & $0.30 \pm 0.98$ & $0.05 \pm 0.31$ & 0.002 \\
\hline
\end{tabular}

GI: Gingival index, PLI: Plaque index, OHIS: Simplified Oral hygiene index, TM: Tooth mobility

The mean periodontal parameters are better in non-denture wearers than denture wearers and they all were statistically significant.

\section{Discussion}

The periodontal status of the teeth adjacent to the denture is important since they support the prosthesis. Thus, there is the need to ensure their periodontal health so as to prevent tooth loss. Studies have shown that plaque induced gingivitis and chronic periodontitis are associated with abutment teeth [6,7]. This study examined periodontal changes on abutment teeth of participants who wear removable partial dentures. 
The mean age group of the study participants was $40 \pm 14.5$ years. This is comparable to studies done among Jordanian and Nigerian adults that reported a mean age of 42.6 years and $45.1 \pm 18.9$ years respectively [16.17]. The mean age in our study contrasts to the studies done in France and Austria that reported mean age of 81.1 years and $61.4 \pm 9.6$ years respectively. Just like our study, the studies done in Jordan and Nigeria were among adults while the France and Austria studies were among institutionalized elderly and those over 60 years of age respectively $[18,19]$.

This study had a female predominance with F:M of 1.4: 1 which is comparable to another study done in Kosovo that reported a F:M of 1.2:1 and in contrast to studies done in Prishtina and Nigeria that had male predominance with F:M ratio of $1: 1.3$ and $1: 1.03$ respectively $[22,16,23]$.

Reports have shown that bacterial plaque is retained in regions covered by dentures because removable prosthesis usually retains food debris and makes oral hygiene maintenance difficult [17-19]. This leads to the accumulation of plaque and calculus or pockets in worse conditions. The use of RPD over time have been documented to cause periodontal reactions such as gingivitis and periodontitis as a result of plaque accumulation with the RPD acting as a nidus. RPDs can encourage the development of dental caries, damage the periodontium, and increase the amount of trauma on the natural teeth as a result of poor oral hygiene, increased plaque and calculus as well as the transmission of excessive forces to the periodontal structures from occlusal surfaces of the RPDs framework [19-21]. In this study, $49(90.7 \%)$ of denture wearers had gingival inflammation around abutment teeth compared to $4.8 \%$ of non-denture wearers.

To maintain good oral hygiene, it is advocated to cleaning of the mouth twice a day and also to have professional scaling and polishing twice a year [22]. Our study noted that more denture wearers cleaned their teeth twice, while the nondenture clean their teeth professionally by having scaling and polishing done.

This study reported that $45(91.8 \%)]$ of the participants' abutment teeth had mild inflammation compared to 2 (4.8\%) of non-denture wearers. Half of the denture wearing participants had fair oral hygiene. This is not surprising as Some studies reported that bacterial plaque is retained in regions covered by the dentures because removable prosthesis usually retains food debris and makes oral hygiene maintenance difficult, leading to the formation of plaque and calculus or even pockets in worse conditions [23-25]. To avoid this accumulation and improve oral health, clinical studies reported that regular examinations, reinstructions, remotivating of patients on the need for optimal oral hygiene maintenance will not cause periodontal changes in abutment teeth [26-30]. It was reported that patients who received periodic maintenance care 4 times annually were able to maintain good periodontal conditions [30].

In our study recession was only found in RPD wearers; although in only about 13 percent of them. A study done in Hong Kong reported a high prevalence of gingivitis, plaque, and gingival recession, especially in dento-gingival surfaces in close proximity (within $3 \mathrm{~mm}$ ) to the dentures [30]. The Kosovo study reported gingival recession in $72.5 \%$ of the denture wearers. ${ }^{23}$ Other studies reported gingival recession after 4-5 years of wearing RPD and concluded that gingival recession appears to increase gradually with age [18,31].

In our study, 13 percent of our participants had tooth mobility of the abutment teeth. The non-denture wearers had no tooth mobility. A 4-year longitudinal study of RPD patients reported that denture wearers had on the average $18 \%$ of their teeth mobile with a $25 \%$ tendency for increased mobility by the end of the study period [32]. The Kosovo study reported tooth mobility of various degrees based on type of denture support among 42.9\% of their participants [23].

Though, there is no clinical evidence to indicate that torquing forces transmitted to the abutment teeth from distal extension RPDs posed any threat to the periodontal status, and laboratory models could not accurately predict actual forces in vivo and their effects on oral structures but literature has shown that traumatic forces on teeth will cause attachment loss in the presence of plaque and inflammation. It has been reported that an initial increase in tooth mobility may be the result of adaptive, non-pathologic changes [33].

\section{Conclusion}

Our study reported significant periodontal changes in the abutment teeth of RPD wearers

The periodontal inflammation, tooth recession and mobility in denture wearers were worse than in non-denture wearers. Thus, removable partial denture wearers need to be motivated for more adequate oral hygiene practises in order to eliminate the periodontal damages caused by RPDs. Regular recall system should also be instituted for them so as to monitor their periodontal health. 


\section{Compliance with ethical standards}

\section{Acknowledgments}

Drs Oviawe for contribution to data collection.

\section{Disclosure of conflict of interest}

The authors declare no conflict of interest.

\section{Statement of informed consent}

Informed consent was obtained from all individual participants included in the study.

\section{References}

[1] Turgut Cankaya Z, Yurdakos A, Gokalp Kalabay P. The association between denture care and oral hygiene habits, oral hygiene knowledge and periodontal status of geriatric patients wearing removable partial dentures. Eur Oral Re.s 2020; 54(1): 9-15.

[2] Do Amaral BA, Barreto AO, Gomes Seabra E, Roncalli AG, da Fonte Porto Carreiro A, de Almeida EO. A clinical follow-up study of the periodontal conditions of the RPD abutment and non-abutment teeth. J Oral Rehabil. 2010; 37(7): 545-552.

[3] Ellakwa A. Damage Caused by Removable Partial Dentures: Reality? Dentistry. 2012: 2(4); e107.

[4] Dhingra K. Oral rehabilitation considerations for partially edentulous periodontal patients. J Prosthodont. 2012; 21(6): 494-451.

[5] Bergman B. Caries, periodontal and prosthetic findings in patients with removable partial dentures: a ten-year longitudinal study. J Prosthet Dent. 1982; 48: 506-510.

[6] Zlataric DK, Celebic A, Valentic-Peruzovic M. The Effect of Removable Partial Dentures on Periodontal Health of Abutment and Non-Abutment Teeth. J Periodontol. 2002; 73(2): 137-144.

[7] Rocha EP, Francisco SB, Del Bel Cury AA, Cury JA. Longitudinal study of the influence of removable partial denture and chemical control on the levels of Streptococcus mutans in saliva. J Oral Rehabil. 2003; 30(2): 131-138.

[8] Ribeiro DG, Jorge JH, Varjão FM, Pavarina AC, Garcia PP. Evaluation of partially dentate patients' knowledge about caries and periodontal disease. Gerodontology. 2012; 29(2): e253-e258.

[9] Vanzeveren C, D'Hoore W, Bercy P, Leloup G. Treatment with removable partial dentures: a longitudinal study. Part II. J Oral Rehabil. 2003; 30(5): 459-469.

[10] Bergman B, Hugoson A, Olsson CO. Caries, periodontal and prosthetic findings in patients with removable partial dentures: a ten-year longitudinal study. J Prosthet Dent. 1982; 48(5): 50614.

[11] Romano F, Perotto S, Bianco L, Parducci F, Mariani GM, Aimetti M. Self-Perception of Periodontal Health and Associated Factors: A Cross-Sectional Population-Based Study. Int J Environ Res Public Health. 2020; 17 (8): 2758.

[12] Velsko IM, Yates JA, Aron F, Hagan RW, Frantz LAF, Loe L, et al. Microbial differences between dental plaque and historic dental calculus are related to oral biofilm maturation stage. Microbiome. 2019; 7(1): 102.

[13] Bahal P, Malhi M, Shah S, Ide M. Managing the consequences of periodontal diseases/treatment: gingival recession. Dental Update. 2019; 46(10): 966-977.

[14] Oremosu OA, Umesi DC, Savage OH. Pattern of tooth replacement and colour choice among patients in a Nigerian teaching hospital. Nigerian Quarterly Journal of Hospital Medicine. 2014; 24(2): 169-174.

[15] Olusile AO, Esan TA. Pattern of demand of removable partial dentures in Ile-Ife. Nigerian Journal of Health Sciences. 2002; 2: 6-8.

[16] Arigbede A0, Taiwo J0. Pattern of demand for acrylic denture. The Nigerian Health J. 2011; 11(2): 47-50.

[17] Tramini P, Montal S, Valcarcel J. Tooth loss and associated factors in long-term institutionalised elderly patients. Gerodontology. 2007; 24(4): 196-203. 
[18] Hamasha AA, Sasa I, Al-Qudah M. Risk indicators associated with tooth loss in Jordanian adults. Community Dent Oral Epidemiol. 2000; 28(1): 67-72.

[19] Slade GD, Gansky SA, Spencer AJ. Two-year incidence of tooth loss among South Australians aged 60+ years. Community Dent Oral Epidemiol. 1997; 25(6): 429-437.

[20] Vysniauskaité S, Kammona N, Vehkalahti MM. Number of teeth in relation to oral health behaviour in dentate elderly patients in Lithuania. Gerodontology. 2005; 22(1): 44-51.

[21] Esan TA, Olusile AO, Akeredolu PA, Esan AO. Socio-demographic factors and edentulism: the Nigerian experience. BMC Oral Health. 2004; 4(1): 3.

[22] Dula LJ, Shala KS, Pustina-Krasniqi T, Bicaj T, Ahmedi EF. The influence of removable partial dentures on the periodontal health of abutment and non-abutment teeth. Eur J Dent. 2015; 9(3): 382-386.

[23] Dula LJ, Ahmedi EF, Lila-Krasniqi ZD, Shala KS. Clinical Evaluation of Removable Partial Dentures on the Periodontal Health of Abutment Teeth: A Retrospective Study.The Open Dentistry Journal. 2015; 9: 132-139.

[24] Kapur KK, Deupree R, Dent RJ, Hasse AL. A randomized clinical trial of two basic removable partial denture designs. Part I Comparisons of five-year success rates and periodontal health. J Prosthet Dent. 1994; 72: 268-82.

[25] Shetty MS, Jain S, Prabhu UM, Kamath AG, Dandekeri S, Ragher M et al. Assessment of Periodontal Disease Among the Dental Prosthetic and Nonprosthetic Wearers in an Adult Rural Population in Mangalore Taluk, South India. J Pharm Bioallied Sci. 2019; 11(2): S175-S179.

[26] Bergman B, Hugoson A, Olsson CO. A 25-year longitudinal study of patients treated with removable partial dentures. J Oral Rehabil. 1995; 22: 595-599.

[27] Kern M, Wagner B. Periodontal findings in patients 10 years after insertion of removable partial dentures. J Oral Rehabil. 2001; 28: 991-997.

[28] Kapur KK, Deupree R, Dent RJ, Hasse AL. A randomized clinical trial of two basic removable partial denture designs. Part I: Comparisons of five-year success rates and periodontal health. J Prosthet Dent. 1994; 72: 268282.

[29] Bergman B, Ericson A, Molin M. Long-term clinical results after treatment with conical crown-retained dentures. Int J Prosthodont. 1996; 9: 533-538.

[30] Koyama S, Hanabuchi S, Fuji T, Ina Y, Yoda N, Hanawa S, et al. The difference between baseline and 5-year examinations at recall in PCR, PD, tooth mobility, and BRL of abutment teeth in subjects who had received periodic maintenance care more than 4 times/year. Ann Jpn Prosthodont Soc. 2012; 4: 59-67.

[31] Yeung AL, Lo EC, Chow TW, Clark RK. Oral health status pf patients 5 to 6 years after placement of cobaltchromium removable partial dentures. J Oral Rehabil. 2000; 27: 183-189.

[32] Wright PS, Hellyer PH. Gingival recession related to removable partial dentures in older patients. Prosthet Dent. 1995; 74(6): 602-607.

[33] Hussain KA, Azzeghaibi SN, Tarakji BRSS, Sirajuddin S, Prabhu SS. Iatrogenic Damage to the Periodontium Caused by Removable Prosthodontic Treatment Procedures: An Overview. Open Dent J. 2015; 9: 187-189. 